\title{
Water Mass Dynamics in Cryolithozone \\ of Central Siberia Based \\ on Grace Remote Sensing Data
}

\author{
Sergey T. Im*a,b,cand Viacheslav I. Kharuk ${ }^{\text {a,b }}$ \\ ${ }^{a} V . N$. Sukachev Institute of Forest SB RAS \\ 50/28 Academgorodok, Krasnoyarsk, 660036, Russia \\ ${ }^{b}$ Siberian Federal University \\ 79 Svobodniy, Krasnoyarsk, 660041, Russia \\ 'iberian State Aerospace University M.F. Reshetnev \\ pr. Them. newspaper «Krasnoyarsk worker», \\ Krasnoyarsk, 660014, Russia
}

Received 24.02.2015, received in revised form 10.04.2015, accepted 21.05.2015

An investigation of application of gravimetric data from GRACE twin satellite mission for estimation of equivalent water thickness anomalies dynamics caused by climate change were carried out. Significant trends of water mass for the period 2003-2012 were revealed. During 20032008, positive trends of water mass dynamics with subsequent stabilization linked to dynamic of precipitation, temperature and potential evapotranspiration were observed. Dependence of rate of water accumulation from soil properties was determined. Significant content of gravel in soil accelerates water accumulation $(r=0.72, \alpha<0.02)$ and increased content of clay decreases rate of water accumulation $(r=-0.69 \ldots-0.77, \alpha<0.02)$. Determined tendencies in water mass dynamics, probably, indicates increasing of permafrost thaw depth in Taimyr Peninsula, in Central Siberian Plateau and in the western part of the Lena River's basin.

Keywords: permafrost, Central Siberia, gravity data, GRACE.

DOI: 10.17516/1999-494X-2015-8-6-734-743.

(C) Siberian Federal University. All rights reserved

* Corresponding author E-mail address: stim@ksc.krasn.ru 


\title{
Изменение водной массы в криолитозоне Средней Сибири по данным дистанционного зондирования GRACE
}

\author{
С.Т. Им ${ }^{\mathrm{a}, \tilde{0}, \mathbf{s}}$, В.И. Харук ${ }^{\mathrm{a}, \boldsymbol{0}}$ \\ ${ }^{a}$ Институт леса им. В.Н. Сукачева СО РАН \\ Россия, 660036, Красноярск, Академгородок, 50/28 \\ ${ }^{6}$ Сибирский федеральный университет \\ Россия, 660041, Красноярск, пр. Свободныий, 79 \\ ${ }^{8}$ Сибирский государственный аэрокосмический университет \\ им. академика М.Ф. Решетнева \\ Россия, 660014, Красноярск, пр. им. газетьл «Красноярский рабочий»
}

\begin{abstract}
Проведено исследование возможности применения данных гравиметрии со спутников GRACE для оченки динамики водной массы в связи с климатическими изменениями в криолитозоне Средней Сибири. Обнаружены достоверные тренды изменения водной массы в период с 2003 по 2012 г. В 2003-2008 г2. наблюдались положительные тренды водной массы с последующей стабилизацией, связанной с динамикой количества осадков, температурой воздуха и величиной потенциальной эвапотранспирации. Установлено, что скорость нарастания водной массы зависит от состава почвогрунтов. Значительное содержание гравия способствует скорости накопления влаги $(r=0.72, \alpha<0.02)$, а содержание глинь уменьшает $(r=-0.69 \ldots-0.77, \alpha<0.02)$. Выявленные тенденции динамики аномалий водной массы, вероятно, указывают на увеличение глубины оттаивания почвогрунтов на n-ове Таймыр, на Среднесибирском плато и в западной части бассейна р. Лена.
\end{abstract}

Ключевые слова: Средняя Сибирь, гравиметрия, водная масса, GRACE.

\section{Введение}

Зона многолетнемерзлых грунтов, в которой расположено более 60 \% территории России, особенно чувствительна к изменениям температуры [1]. В последние четыре десятилетия в этой части России наблюдался рост температуры мерзлых грунтов на $0.3-2{ }^{\circ} \mathrm{C}$ [2]. Прогнозируемый к концу XXI столетия рост температуры воздуха в Арктике на $7 \ldots 11{ }^{\circ} \mathrm{C}$ приведет к возрастанию глубины сезонного оттаивания, изменениям водного баланса и сокращению вечной мерзлоты [3]. Данные моделирования указывают на вероятное сокращение к концу XXI в. площади вечной мерзлоты на 37-81 \% (модели RCP2.6 и RCP8.5) [3]. Увеличение глобальной температуры на $0.5-1{ }^{\circ} \mathrm{C}$ приведет к деградации ареалов прерывистой и островной мерзлоты в Сибири, а потепление на $\sim 1.5^{\circ} \mathrm{C}$ вызовет существенное оттаивание зоны сплошной мерзлоты выше 60 ․․ [4]. Таяние мерзлоты сопровождается интенсификацией солифлюкции и термокарстовых процессов, что повлияет на инфраструктуру промышленных объектов Сибири, включая нефтегазовые комплексы.

Современные методы дистанционного зондирования Земли (ДДЗ) широко используются в исследованиях обширных территорий, к которым относится криолитозона Средней Сибири. С 2002 г. работает спутниковая программа GRACE (Gravity Recovery and Climate Experiment), которая позволяет измерять аномалии гравитационного поля Земли, связанные с перемещением масс. Применив материалы GRACE, исследователи обнаружили зна-

$$
-735-
$$


чительное сокращение водной массы в ледниках арктической и антарктической зон [5-7]. В мерзлотной зоне Сибири, по данным GRACE, выделены регионы с возрастающими трендами водной массы в начале XXI в. [8]. Маскетт и Романовский [9] показали, что для возвышенных территорий в зоне вечной мерзлоты наблюдаются положительные тренды водной массы, в то время как в низинах - отрицательные. В южной зоне бассейна р. Лена обнаружен рост массы подземных вод [10]. Аналогичное явление наблюдалось на арктическом побережье Аляски, в то время как в бассейне р. Юкон отмечено уменьшение водной массы [11]. По данным GRACE в разных районах Земли отмечено значительное сокращение запасов подземных вод [12].

В данной работе изучена динамика аномалий водной массы в криолитозоне Средней Сибири по материалам гравиметрической съемки GRACE. Оценивалась динамика водной массы в начале XXI в., и анализировалась ее связь с климатическими переменными и параметрами почвогрунтов.

\section{Материалы и методика}

\section{Объект исследования}

Объект расположен в северной части Средней Сибири (площадь $~ 5.3 \cdot 10^{6}$ км$^{2},>90 \%$ расположено в криолитозоне; рис. 1). Территория преимущественно расположена на Среднесибирском плоскогорье и плато Путорана. Климат резко континентальный. Средние зимние температуры минус $(40 \pm 20)^{\circ} \mathrm{C}$ и летние $-(17 \pm 15){ }^{\circ} \mathrm{C}$. Годовые осадки варьируются от 200-400 мм на востоке до 400-600 мм на западе, достигая 700-1000 мм на плато Путорана [13]. Высота от 150 до 1700 м над уровнем моря. На севере территории преобладает тундра. В северной лесопокры-

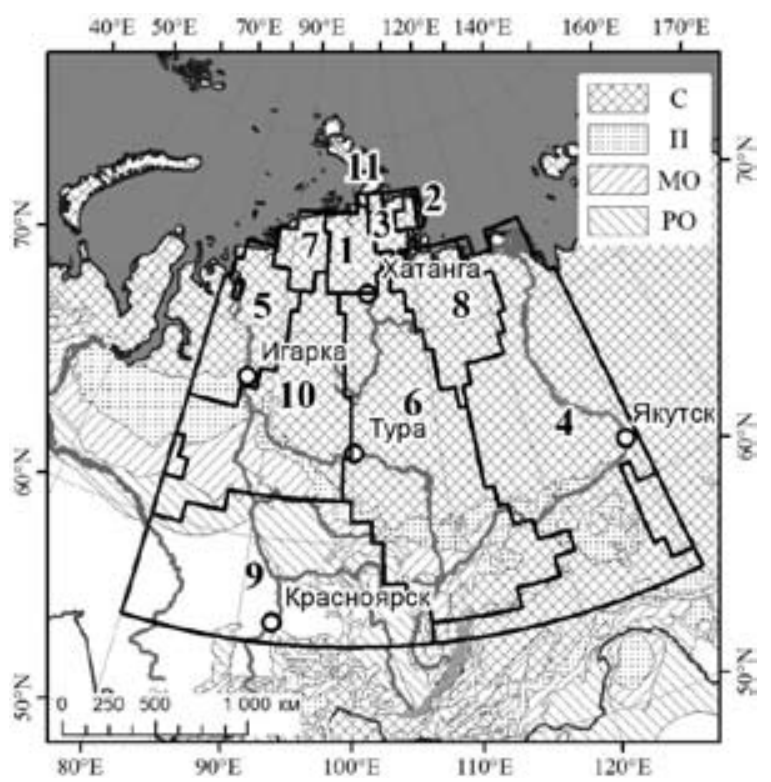

Рис. 1. Объект исследования с зонами условно-однородных аномалий водной массы (1-11). Подложка карта мерзлотных зон: С - сплошная; П - прерывистая; МО - массивно-островная; РО - островная и редкоостровная 
той части доминирует лиственница (Larix sibirica, L. dahurica); на юге и юго-западе - смешанные древостои (лиственница, сосна (Pinus silvestris), кедр (Pinus sibirica), пихта (Abies sibirica), ель (Picea obovata) и мелколиственные породы).

\section{Гравиметрические данные}

В результате сотрудничества американских (NASA) и германских (DLR) ученых в марте 2002 г. запущена космическая программа гравиметрических измерений Земли - GRACE (Gravity Recovery and Climate Experiment). Программа состоит из двух идентичных спутников, летящих на полярной орбите и позволяющих измерять аномалии гравитационного поля Земли, связанные с перемещением водных масс (http:/grace.jpl.nasa.gov).

В работе анализировались аномалии водной массы, по данным GRACE, за период с января 2003 по июнь 2013 г., полученным с сайта http:/grace.jpl.nasa.gov. Материалы съемки представляют среднемесячные аномалии водного эквивалента массы (АВЭМ) относительно базового периода с января 2004 по декабрь 2009 г., с пространственным разрешением один градус

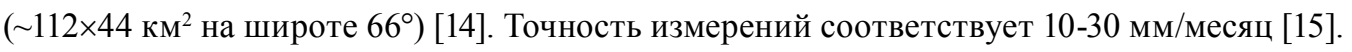

Для выделения зон «однородных» изменений АВЭМ применен метод кластеризации ISODATA к временной серии данных АВЭМ по аналогии с предыдущим исследованием [16].

Для оценки сокращения водных масс оценивались динамики минимальной и остаточной водной массы $\left(W_{r}\right)$, равной разности минимального значения АВЭМ в текущем году $\left(W_{\text {mincur }}\right)$ и предыдущем году $\left(W_{\text {minprev }}\right)$.

\section{Климатические данные}

Применены помесячные данные о температурах, осадках и потенциальной эвапотранспирации (CRU TS 3.21) с сайта http://badc.nerc.ac.uk [17]. Материалы представляют собой гриды с пространственным разрешением 0.5 градуса. Динамики климатических переменных (рис. 2) сравнивались с динамикой АВЭМ.

\section{Картографические материаль}

Мерзлотные зоны определены в соответствии с картой зон вечной мерзлоты Северного полушария [18] (рис. 1) [http://nsidc.org/data].
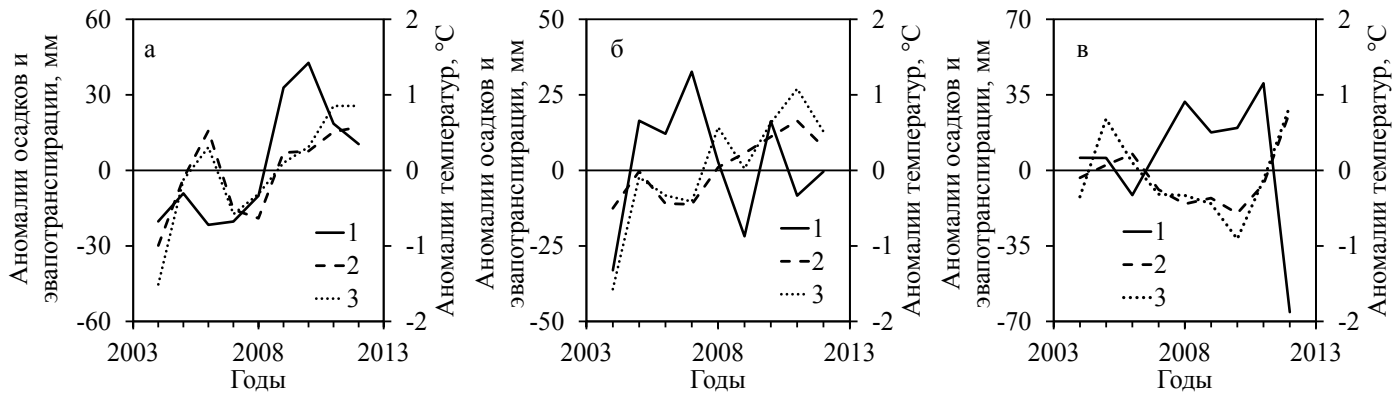

Рис. 2. Типичные динамики за летний период осадков (1), потенциальной эвапотранспрации (2) и температур (3): а - тундра (зона 3); б - бассейн р. Лена (зона 4); в - зона островной мерзлоты (зона 9) 
Связь динамика АВЭМ с параметрами почвогрунтов анализировались на основе цифровой карты почвогрунтов Harmonized World Soil Dataset [19]. Для каждой однородной зоны рассчитывался средний уровень дренажа, в также процентное содержание гравия, песка, глины и ила для верхнего (0-30 см) и нижнего (30-100 см) слоев грунта.

Классы наземного покрова определялись по карте растительности Евразии (http://terranorte. $\mathrm{ru})$.

\section{Результаты и обсуждение}

Динамика аномалий водной массы

В пределах анализируемой территории выделено 11 условно однородных зон динамики АВЭМ (рис. 1). Зоны представлены двумя группами, расположенными преимущественно в тундре (зоны $1-3,5,7,11)$ либо вне её (зоны $4,6,8-10)$. Все тундровые участки находятся в зоне сплошной мерзлоты. Девятая зона является уникальной, ее значительная часть расположена вне криолитозоны.

В динамике АВЭМ большинства зон наблюдается два периода (рис. 3): положительный тренд с 2003 по 2008-2009 гг., с последующей стабилизацией или падением величины АЭВМ. В последний период в зонах, расположенных в тундре (исключая зону 5), наблюдался рост дисперсии АВЭМ (на $30-70 \% ; \alpha<0.05)$. В этот же период замечен негативный тренд минимальной величины АВЭМ (исключая зону 7).

В период 2003-2008 гг. значительное накопление водной массы было в тундровых зонах (до 20 мм/год). В лесопокрытых зонах наибольшая величина роста АВЭМ наблюдались в среднем течении Енисея и Оби (зона № 9; рис. 1; +14 мм/год). В последующие годы (2009-2013) во всех тундровых зонах происходило снижение величины тренда с одновременным существенным (на 30-70 \%) возрастанием дисперсии АВЭМ, происходившим на фоне значительного (до 40 \%) роста вариабельности осадков. Вероятно, в тундровых зонах в 2009-2012 гг. рост количества осадков (рис. 2а) увеличил перенос тепла в нижние слои почвогрунтов и, следовательно, увеличил глубину оттаивания мерзлотных грунтов, что привело к стоку растаявших водных масс (рис. 3a) на фоне увеличенного испарения за счет роста температур (рис. 2а). Положительные тренды водной массы в период 2003-2008 гг. для верховьев Оби и Лены обнаружены другими исследователями $[8,9]$. Динамика АВЭМ указывает на возрастание величины стока реки Ени-
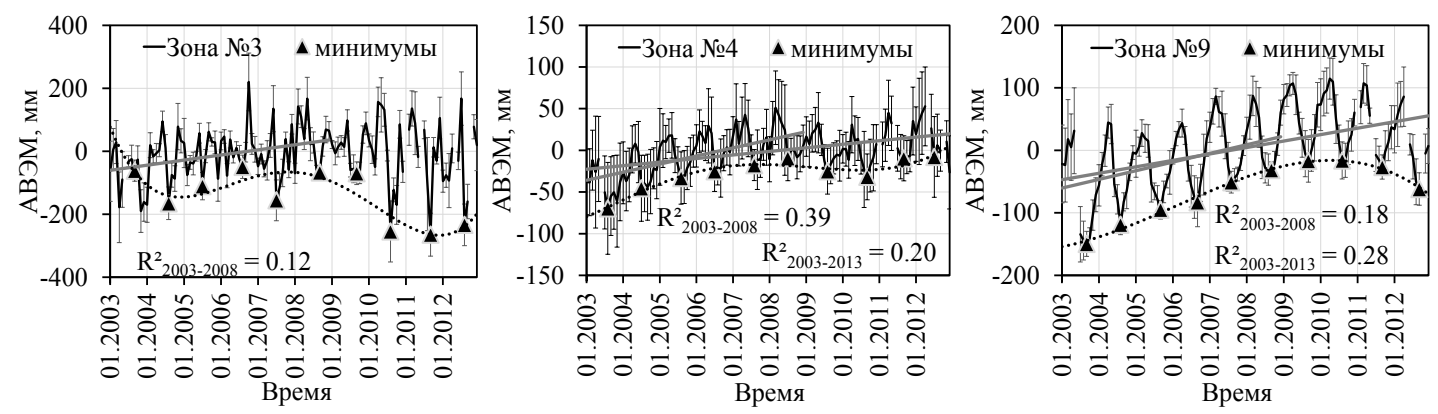

Рис. 3. Типичные временные серии АВЭМ. Серые прямые линии - тренды АВЭМ $(\alpha<0.05)$. Точечные линии - аппроксимации минимальных значений АВЭМ 
сей в начале XXI в., что подтверждается прямыми измерениями величины стока [20]. Возрастание стока обусловлено преимущественно увеличением осадков (что происходило во всех зонах в период с 2003 по 2008 г.), нежели высвободившейся при оттаивании мерзлоты водной массе. К такому заключению пришли и другие исследователи [21].

Отрицательные значения остаточной водной массы - $W_{r}$; (рис. 4) указывают на сокращение водной массы в почвогрунтах. Баланс остаточной массы для крайних северных зон (№ 1-3, 11) за период наблюдений отрицателен (-205 мм); для центральных и южных зон (№ 4-6, 9, 10) составляет +74 мм. Минимумы остаточной водной массы в тундровых зонах соответствуют
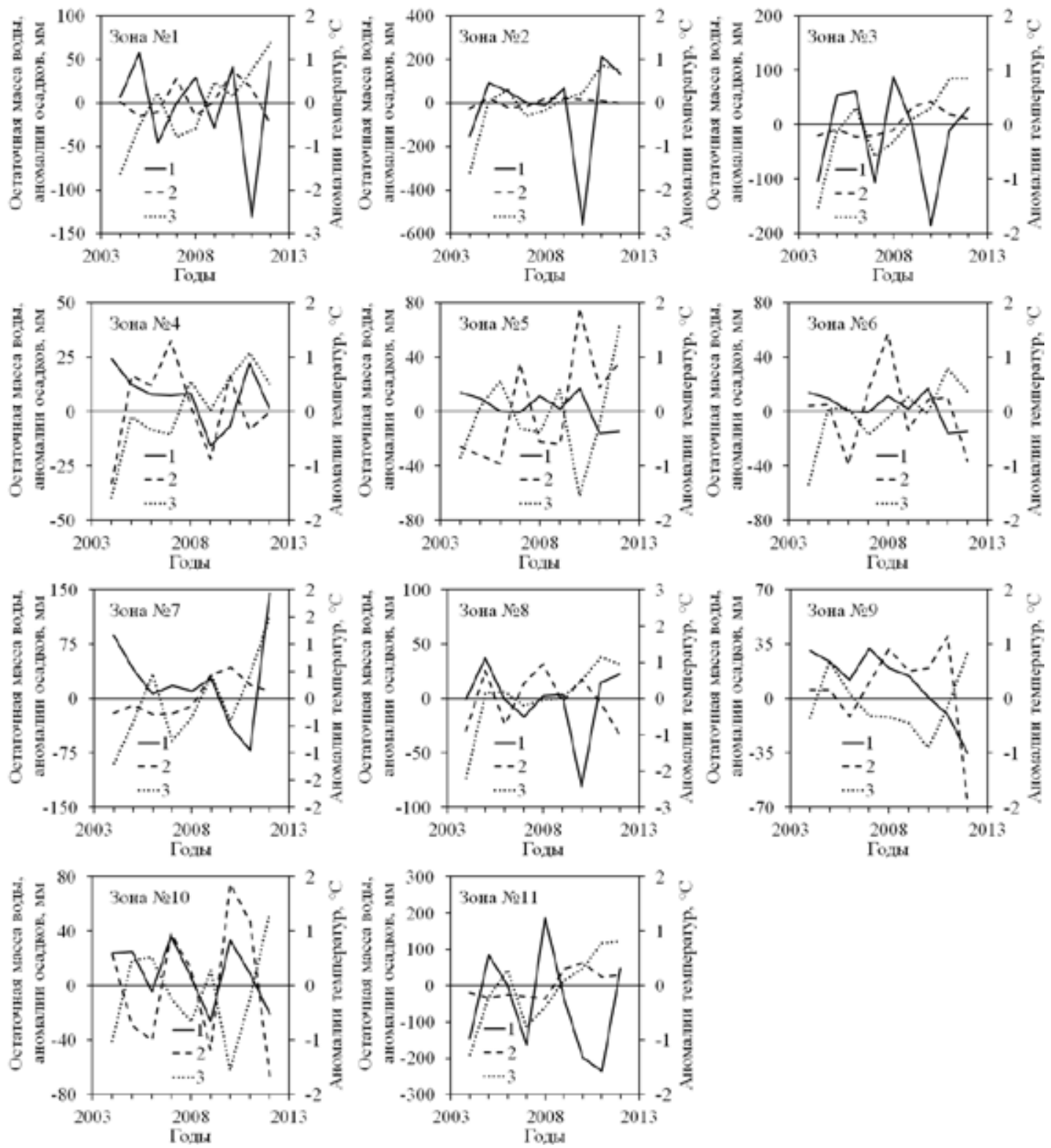

Рис. 4. Динамика остаточной водной массы, аномалий летних осадков и температуры: 1 - остаточная водная масса $W_{r} ; 2$ - аномалии летних осадков; 3 - аномалии летних температур 
2009-2012 гг. (рис. 4), что на фоне стабильности и роста осадков указывает на увеличение стока и испарения.

\section{Динамика АВЭМ и параметры почвогрунтов}

Нарастание массы воды в период 2003-2008 гг. положительно связано с содержанием гравия в верхнем (0-30 см; $r=0.73, \alpha<0.02)$ и нижнем (30-100 см; $r=0.72, \alpha<0.02)$ слоях грунта (рис. 5a). С содержанием глины наблюдается отрицательная корреляция - для верхнего слоя $\mathrm{r}=-0.69, \alpha<0.02$; для нижнего слоя $\mathrm{r}=-0.77, \alpha<0.02$; (рис. 5б). Указанное, видимо, обусловлено уровнем дренажа, т.е. гравий и песок позволяют почвогрунтам накапливать выпадающую с осадками влагу, тогда как высокое содержание глины блокирует проникновение воды в глубь почвогрунтов.

\section{Динамика АВЭМ и климатические тренды}

Минимум АВЭМ наблюдается в августе-октябре, максимум - в марте-мае (рис. 6). Водная масса уменьшается в период положительных температур, когда происходит таяние снежных масс. В это время сток воды значительно превосходит количество выпадающих осадков. Интенсивное испарение способствует уменьшению водной массы.
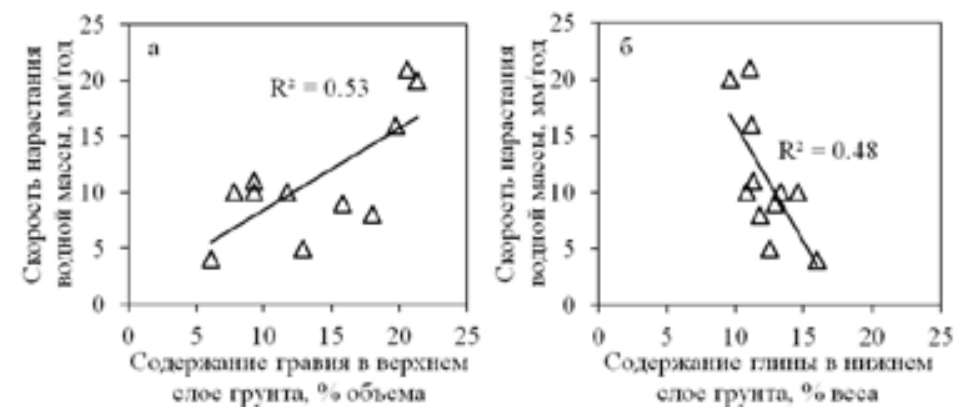

Рис. 5. Зависимость скорости нарастания водной массы от содержания (а) гравия в верхнем слое грунта и глины (б) в нижнем (период: 2003-2008 гг). Тренды значимы $(\alpha<0.02)$
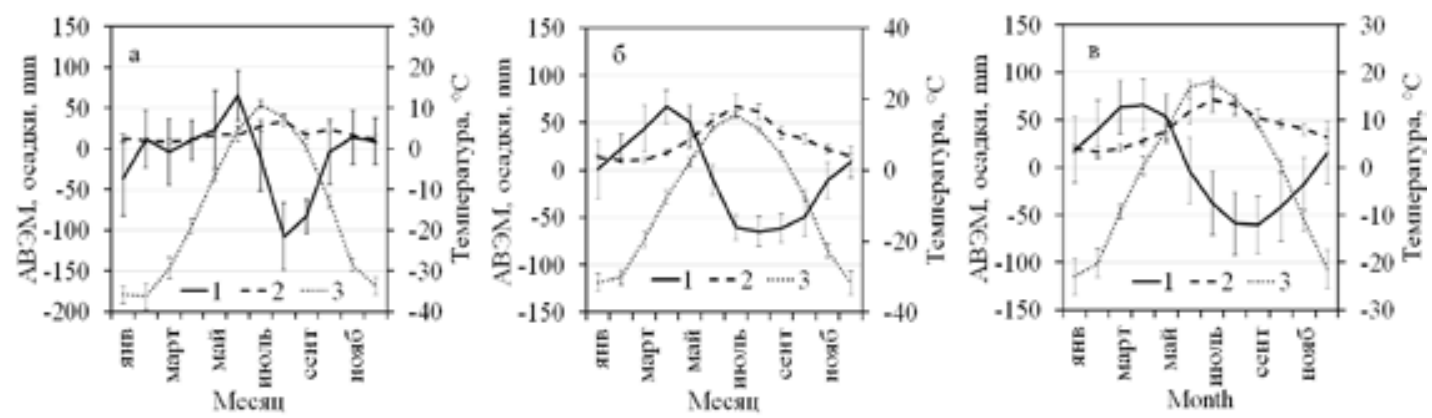

Рис. 6. Типичная сезонная динамика осадков, температур и АВЭМ: а - тундра (типично для 1, 2, 3, 7 и 11 зон); б - зоны, включающие леса и лесотундру (типично для 4, 5, 6, 8 и 10 зон); в - зона № 9 с островной мерзлотой; 1 - АВЭМ; 2 - суммарные осадки; 3 - средние температуры. Стандартные отклонения показаны рисками 
Для зоны № 10, расположенной преимущественно в Среднесибирском плато, обнаружена положительная связь динамики остаточной водной массы $W_{r}$ с годовыми и летними осадками $\left(\mathrm{R}_{\text {Спирмена }}=0.83-0.78\right)$ (рис. 4) и отрицательная - с летней потенциальной эвапотранспирацией $\left(\mathrm{R}_{\text {Спирмена }}=-0.68\right)$ и годовой потенциальной эвапотранспирацией $\left(\mathrm{R}_{\text {Спирмена }}=-0.63\right)$.

В зонах, расположенных на Крайнем Севере (п-ов Таймыр), тренды температур и осадков положительны за весь период наблюдений. В остальных зонах тренд осадков становится отрицательным с 2008 г. (рис. 2). Рост среднегодовых температур на п-ове Таймыр составил $0.24-0.42{ }^{\circ} \mathrm{C} /$ год. Указанное, видимо, способствовало увеличению глубины оттаивания вечной мерзлоты, так как известно, что в теплый период жидкие осадки, проникающие в почвогрунты, способствуют теплопереносу и таянию.

Во всех зонах, за исключением 9 и 10, наблюдался значимый рост величины потенциальной эвапотранспирации, особенно на Таймыре, где ее величина превосходила величину осадков в $1.6-4.4$ раза.

Таким образом, возрастание температуры и осадков, вероятно, вызвало увеличение глубины оттаивания мерзлотного слоя. Также косвенным показателем этого являются величины минимальной и остаточной водной массы $\left(W_{r}\right)$. Величина последней определяется колебаниями влаги в почвогрунтах в бессточных водных резервуарах. На Таймыре наблюдался падающий тренд минимальной и остаточной водной массы. За период наблюдений (2003-2012 гг.) дефицит $W_{r}$ составил 250 мм. Это косвенно указывает на возрастание глубины оттаивания почвогрунтов. Для более точных оценок необходимо иметь фактические данные о влажности почвогрунтов, стоке рек и величине эвапотранспирации.

В южных зонах суммарная остаточная водная масса за период наблюдений составляет примерно 70 мм (рис. 4). В данном случае индикатором возрастания таяния вечной мерзлоты может служить значимый тренд роста водной массы в период 2003-2008 гг. (рис. 3). В этих зонах, включающих Среднесибирское плато и большую часть бассейна р. Лена, почвогрунты способны поглощать большие массы жидких осадков. При оттаивании почвогрунтов их поглощающая способность возрастает за счет того, что ранее недоступные для проникновения воды участки вскрываются и заполняются водой. При этом известно, что плотность льда ниже, чем у жидкой воды, на 5 \%, т.е. освободившееся ото льда пространство может занять жидкая вода с массой на $5 \%$ больше. Таким образом, в Среднесибирском плато и бассейне р. Лена в период 2003-2008 гг., вероятно, возрастала глубина оттаивания. Ландер и др. [22] также отмечали увеличение активного слоя при возрастании водной массы.

\section{Заключение}

В данной статье проведено исследование возможности применения данных гравиметрии со спутников GRACE для оценки динамики водной массы в связи с климатическими изменениями в криолитозоне Средней Сибири. Обнаружены достоверные тренды изменения водной массы в период с 2003 по 2012 г. В 2003-2008 гг. наблюдался положительный тренд АВЭМ (5-21 мм/год; $\left.\mathrm{R}^{2}=0.04-0.39, \alpha<0.09\right)$, связанный с динамикой количества осадков, температурой воздуха и величиной потенциальной эвапотранспирации. В следующий период (20092013 гг.) во всех тундровых зонах зафиксировано существенное (на 30-70 \%) возрастание дисперсии АВЭМ (по сравнению с предыдущим периодом), происходившее на фоне значительного 
(до 40 \%) роста вариабельности осадков. Установлено, что скорость нарастания водной массы зависит от состава почвогрунтов. Значительное содержание гравия способствует скорости накопления влаги ( $\mathrm{r}=0.72, \alpha<0.02)$, а содержание глины - уменьшает $(\mathrm{r}=-0.69 \ldots-0.77, \alpha<0.02)$. Выявленные тенденции динамики аномалий водной массы, вероятно, указывают на увеличение глубины оттаивания почвогрунтов на п-ове Таймыр, на Среднесибирском плато и в западной части бассейна р. Лена.

\section{Работа поддержана грантом Правительства РФ № 14.B.25.31.0031.}

\section{Список литературы}

[1] Callaghan T.V., Jonasson S. // Phil. Trans. Roy. Soc. Lond. A. 1995. Vol. 352. P. 259-276.

[2] Romanovsky V.E., Drozdov D.S., Oberman N.G. et. al. // Permafr. Periglac. Process. 2010. Vol. 21. P. 136-155. doi: 10.1002/ppp.683.

[3] IPCC, 2013: Climate Change 2013: The Physical Science Basis. Contribution of Working Group I to the Fifth Assessment Report of the Intergovernmental Panel on Climate Change // Eds.: T.F. Stocker, D. Qin, G.-K. Plattner, M. Tignor, S.K. Allen, J. Boschung, A. Nauels, Y. Xia, Vol. Bex, P.M. Midgley. USA, Cambridge, United Kingdom and New York, NY: Cambridge University Press, 2013. $1535 \mathrm{p}$.

[4] Vaks A., Gutareva O.S., Breitenbach S.F.M. et. al. // Science. 2013. Vol. 340(6129). P. 183-186. doi: 10.1126/science.1228729.

[5] Chen J.L., Wilson C.R., Tapley B.D. // Science. 2006. Vol. 313(5795). P. 1958-1960. doi: 10.1126/ science.1129007.

[6] Barletta V.R., Sørensen L.S., Forsberg R. // The Cryosphere. 2013. Vol. 7. P. 1411-1432.

[7] Groh A., Ewert H. Rosenau R. Fagiolini E. et. al. // Surv. Geophys. 2014. Vol.35. P. 1481-1505. DOI 10.1007/s10712-014-9286-y

[8] Steffen H., Muller J., Peterseim N. // Geodesy for Planet Earth, International Association of Geodesy Symposia. 2012. Vol. 136. P. 597-603.

[9] Muskett R.R., Romanovsky V.E. // Natural Science. 2011. Vol. 3. N 10. P. 827-836.

[10] Velicogna I., Tong J., Zhang T., Kimball J.S. // Geophysical Research Letters. 2012. Vol. 39(9), L09403. doi: 10.1029/2012GL051623.

[11] Muskett R.R., Romanovsky V.E. // Remote Sens. 2011. Vol. 3(2). P. 378-397. doi: 10.3390/ rs3020378.

[12] Famiglietti J.S. // Nature Climate Change. 2014. V.4. P. 945-948 (2014). doi:10.1038/ nclimate2425.

[13] Раковская Е.М., Давыдов М.И. Физическая география России. М.: Владос, 2001. 304 с.

[14] Landerer F.W., Swenson S.C. // Water Resources Research. 2012. Vol. 48(4). doi: 10.1029/2011WR011453.

[15] Long D, Longuevergne L, Scanlon BR. // Water Resour Res 2014. V.50(2). P. 1131-1151. doi:10.1002/2013WR014581

[16] Им С.Т., Харук В.И. // Геофизические процессы и биосфера, 2015.

[17] Harris I., Jones P.D., Osborn T.J., Lister D.H. // Int. J. Climatol. 2013. Vol. 34(3). P. 623-642. doi: $10.1002 /$ joc. 3711 . 
[18] Brown J., Ferrians O.J., Heginbottom J.A., Melnikov E.S. // National Snow and Ice Data Center. Boulder, Colorado USA. Digital media, Boulder. 2002. URL: http://nsidc.org/data/ggd318. html.

[19] FAO/IIASA/ISRIC/ISSCAS/JRC. Harmonized World Soil Database (version 1.2) // FAO, Rome, Italy and IIASA, Laxenburg, Austria, 2012. URL: http://webarchive.iiasa.ac.at/Research/LUC/ External-World-soil-database/HTML

[20] Shiklomanov A.I. // In: Arctic Report Card 2010: Update 2010. Eds.: Richter-Menge J., Overland J.E. 2010. URL: http://www.arctic.noaa.gov/reportcard

[21] Vey S., Steffen H., Müller J, Boike J. // Journal of Geodesy. 2013. Vol. 87(3). P. 287-299. doi: 10.1007/s00190-012-0597-9.

[22] Landerer F.W., Dickey J.O., Güntner A. // Journal of Geophysical Research: Atmospheres (1984-2012), 2010. Vol. 115(D23). doi: 10.1029/2010JD014584. 